\title{
Analysis of Global Demand for Iron Source by Utility of Stock Hypothesis
}

\author{
Sumio KOZAWA, ${ }^{1)}$ Seiichi HAYASHI ${ }^{2)}$ and Fumitaka TSUKIHASHI ${ }^{31}$ \\ 1) Graduate School of Engineering, The University of Tokyo, 7-3-1 Hongo, Bunkyo-ku, Tokyo 113-8656 Japan. \\ 2) Iron Recycling Research, 253-271 Fukawa, Tonemachi, Kitasouma-gun, Ibaraki 300-1622 Japan. \\ 3) Graduate School of Frontier Sciences, The University of Tokyo, 5-1-5-501 Kashiwanoha, Kashiwa, Chiba $277-8561$ Japan.
}

(Received on April 25, 2008; accepted on October 2, 2008)

\begin{abstract}
To forecast iron source demand, the Intensity of Use hypothesis, which assumes that material consumption per capita is a function of GDP per capita, is the most dominant theory in existing studies. However, this hypothesis is not effective for a world one-region model of iron sources. Therefore, we focus our attention on utility, and we suppose that economic growth is a major driver to increase the utility. As the utility of steel sustains for ages after purchase, we formulate the Utility of Stock hypothesis, which assumes that the in-use steel stock is a function of GDP. In this study, the world steel stock was computed and the Utility of Stock hypothesis was tested. Clear correlation is found between the steel stock and the GDP. It leads to the estimation that the world demand for iron ore depends not on the volume of GDP but on the variation of GDP. For the first time with total world figures, the result enables us to rationalize the recent decoupling between the world growth of iron source demand and the economic growth.
\end{abstract}

KEY WORDS: iron source; steel; demand; stock; outlook; mass effect; energy; economy; simulation; modeling.

\section{Introduction}

In a majority opinion, the iron and steel industry is viewed as a mature industry. However, it is time to shift the paradigm of the industry to being viewed as a growing industry in the perspectives of technology as well as quantity. From the viewpoint of mass effect, ${ }^{* 1}$ it is time to accelerate the development of steel technology with a greater unified effort by the industry-academic-government.

The supply and demand of iron source on a global scale have expanded during recent years. The crude steel production of the world, which increases 1.73 times over the last nine years, is 1.34 billion tons in 2007. Iron and steel are major players of structural materials for social infrastructure and foundations for strengthening industrial competitiveness. At the same time, they confront global challenges due to their mass effect such as a recent rapid growth in steel consumption, a large impact on climate change.

As research and development of iron and steel have been made for years, it is not easy to realize a process innovation to reduce energy consumption and carbon-dioxide emissions drastically or a product innovation to increase in strength largely. However, there is still significant potential of technological innovation to solve those global challenges. ${ }^{2}$ It needs a large amount of money for developing new technologies of iron and steel to realize these difficult innovations. Therefore, it is necessary for deciding the amount of R\&D's investment to share a common world outlook for iron source demand among the government, industry and academia.

As already reported, ${ }^{1)}$ we showed the importance of mass effect by proposing the "equation of mass effect" (tentative name) and pointed out remaining issues concerning world outlook for iron source as follows. Priority issues are to upgrade a demand model rather than considering supply constraint and therefore to consider a one-region world model by focusing on the utility of steel which comes from stocks rather than flows.

In this article, existing models of steel stock will be typified and then the total world stock of steel will be computed in the simplest method for estimation. We will also consider whether it is possible to specify and quantify the economic growth as a major factor of the steel stock computed. From the results of these considerations, we will discuss whether a one-region world model (total world figures) can explain the recent decoupling between the world growth of iron and steel production and the economic growth.

\section{Issues Concerning World Outlook for Iron Source}

\subsection{Problem of Conventional Intensity of Use Hypoth-} esis

As already reported, ${ }^{1)}$ the Intensity of Use hypothesis, which assumes that material consumption per capita (or

\footnotetext{
*1 In this article, "mass effect" represents a volume of transaction and its effect on the economy and society.

$*^{2}$ For example, theoretical strength of steel is regarded as $40000 \mathrm{MPa}$, which is ten times as large as $4000 \mathrm{MPa}$ as of this date.
} 
material consumption per GDP) is a function of GDP per capita, is the most common theory in modeling future demand for material of the country or region under consideration. Some studies have empirically shown that the IU curve (material consumption per capita or material consumption per GDP) for a number of materials has an inverse-U or bell shape when plotted as function of per capita income of a country (Fig. 1). ${ }^{1-6)}$

Some researchers, for example Vurren et al. ${ }^{5)}$ and Neelis et al., ${ }^{2)}$ explain an inverse-U shape of the IU curve by using three arguments. ") "The first argument is that the production composition of income (economic structure) of a country varies in different stage of a country's development. In early stages of development, economies largely rely on agriculture with low material requirements. When a country develops, the demand for basic infrastructure (building, transportation equipments etc.) increases and the share of material-intensive sectors in the economy grows. As development further continues, consumer preferences shift to less material-intensive products, causing the intensity of use to go down, resulting in the observed inverse-U shape of the IU as function of per capita income, especially for products that are mainly used in the production of infrastructure such as metals and cement. The second argument used in the explanation of the inverse- $U$ shape is more related to the material composition of product and explains the observed inverse-U shape by suggesting that the material demand ex-

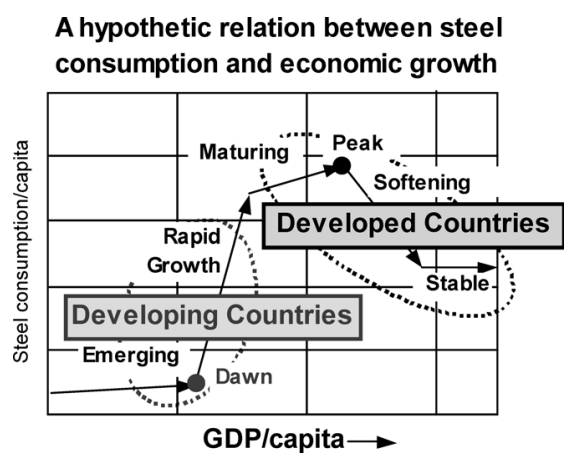

Fig. 1. Intensity of Use hypothesis for steel. ${ }^{1)}$ perience phases in which old, lower quantity materials linked to mature industries undergo replacement by higher quantity or technologically more advanced materials. For individual materials, this lead to phases of expanding use (the new material substitutes existing materials), stabling use (demand for the main end-use of the material saturates) and declining use (the material is increasingly being substituted by other materials). A third additional argument, often used to explain the declining intensity of use in developed countries is the continuously increased efficiency of material use, leading to a more efficient use of certain materials over time."

However, some of those studies, for example Vurren et al. ${ }^{5)}$ point out at the same time that the Intensity of Use hypothesis is not effective for the total world figures (a one-region world model). Furthermore, the Intensity of Use hypothesis is effective for some countries, but is not so much effective for other countries. For example, the IU curve for steel of the USA has a good inverse-U shape but that of Japan does not have a good inverse-U shape, and it led to the result that the assumed values for crude steel demand of Japan in 1977 and 1990 by the government of Japan deviated from the actual values. ${ }^{1)}$

\subsection{Relationship between Demand for Iron Source and Economic Growth}

Although the total world production of iron and steel, which is virtually equal to the total world consumption, demonstrates an upward trend, decoupling relation is observed between the trends of worldwide iron and steel production and the economic trends (GDP ppp ${ }^{* 3}$ ) (Figs. 2 and 3). While the world GDP ppp has increased continuously, the worldwide crude steel production had expanded until the oil shock in 1973, then crawled around 700 million tons during almost 30 years, and has increased again: above 800 million tons in 2000, 900 million tons in 2002, 1 billion tons in 2004, 1.1 billion tons in 2005, 1.2 billion tons in 2006 , and 1.3 billion tons in 2007. From these figures, it is difficult to foresee whether the worldwide iron and steel production will continue its rapid growth or crawl again in

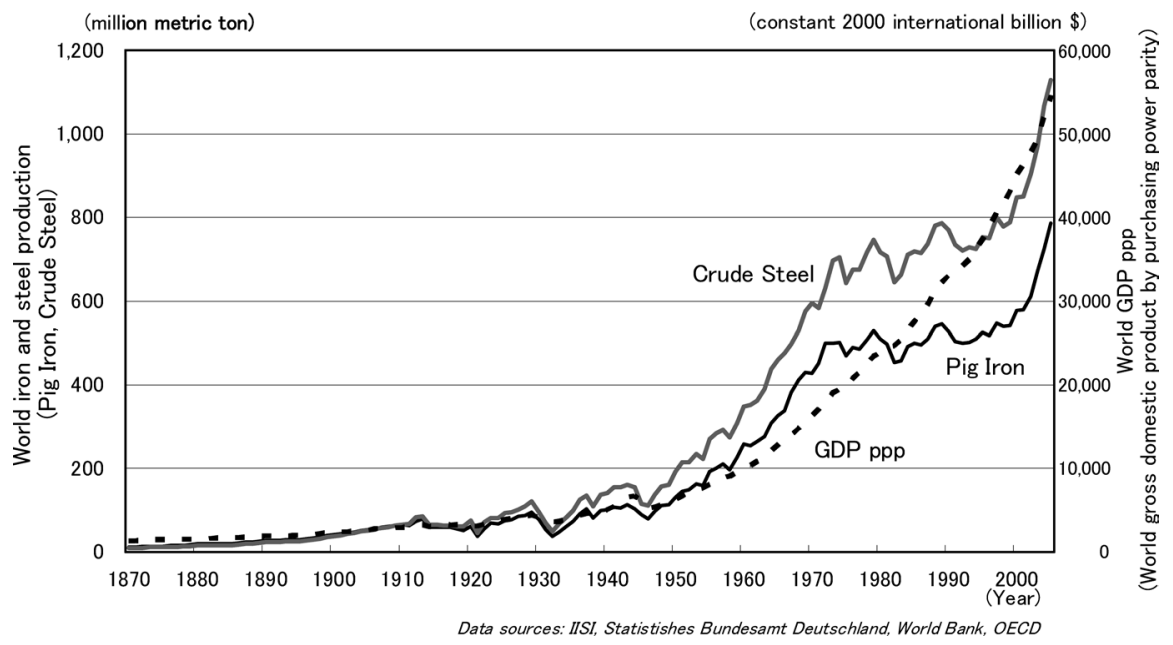

Fig. 2. World iron and steel production, GDP ppp (gross domestic product by purchasing power parity), 1870-2005.

\footnotetext{
*3 “GDP ppp" represents gross domestic product by purchasing power parity. The purchasing power parity (ppp) theory uses the long-term equilibrium exchange rate of two currencies to equalize their purchasing power, which was developed by Gustav Cassel in 1920. PPP exchange rates are especially useful when official exchange rates are artificially manipulated by governments.
} 


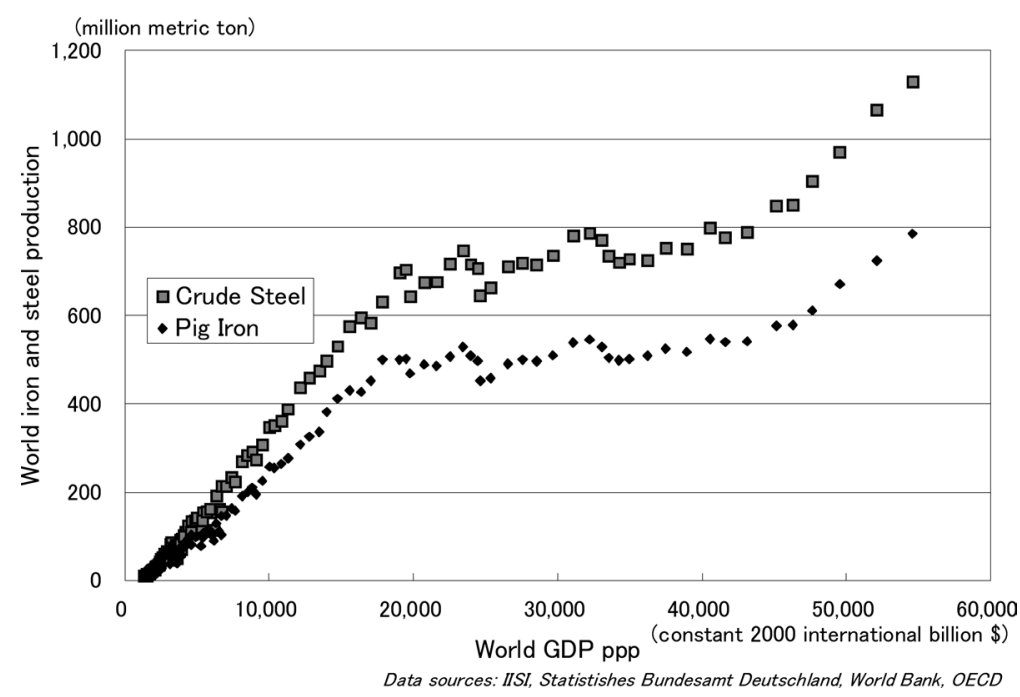

Fig. 3. Relationship between World GDP ppp (gross domestic product by purchasing power parity) and Iron \& Steel production, 1870-2005.

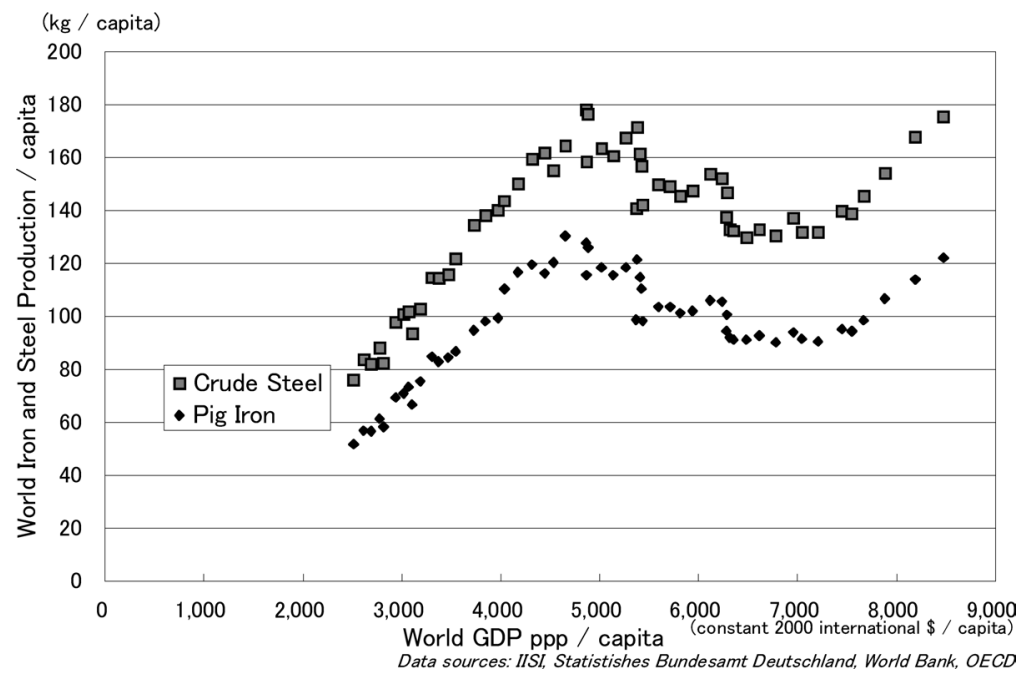

Fig. 4. Relationship between World GDP ppp (gross domestic product by purchasing power parity)/capita and Iron \& Steel production/capita, 1950-2005.

the near future, even if the world GDP will increase continuously.

Figure 4 shows the IU curve (material consumption per capita) for pig iron and crude steel when plotted as function of per capita income of the world. This IU curve does not have a typical inverse-U or bell shape, as the phase of reexpanding use has been observed recently after that of stabling use. The Intensity of Use hypothesis is not effective for the total world figures of iron and steel to predict the IU curve will go up or go down when development (income per capita) further continues in the future.

\subsection{Existing Studies on World Outlook for Iron Source and Other Sources}

Table 1 is a comparison of existing models to forecast crude steel consumption. ${ }^{2-7)}$ All models use the Intensity of Use hypothesis, which assumes that material consumption per GDP or capita is a function of GDP per capita. They project worldwide crude steel consumptions in 2030 from 1.32 to 3.00 billion tons. Except one group of researchers, Vuuren et al., the data ranges 1.32 to 1.98 billion tones.
Existing studies on world outlook for iron source, especially by international organizations and governments, are fewer than those on energy outlook. Furthermore, these existing studies may not be enough in points such as testing the validity with real data and continuous improvement of models. ${ }^{1)}$

With regard to energy outlook, as already reported, ${ }^{1)}$ several international organizations and governments share the view that the growth rate of global energy demand will be around 2\% (1.9-2.3\%) until 2020. The International Energy Agency has reviewed its previous forecasts and errors between the assumed values and the actual values have been within $2.2 \%$ since 1993 . The International Energy Agency has concluded that the precision of forecasts is due to the relation between the world economic growth (GDP ppp) and the energy use (primary energy demand), which is clear and predictable. ${ }^{8)}$ With regard to paper, the world paper consumption per capita is a clear function of the world GDP per capita, according to a report financed by the European Commission. ${ }^{9)}$ 
Table 1. Comparison of world steel forecasts for crude steel consumption.

\begin{tabular}{|c|c|c|c|c|c|c|}
\hline & Neelis ${ }^{2)}$ & Hidalgo $^{3)}$ & VLEEM II ${ }^{4)}$ & Vuuren $^{5)}$ & Kosugi $^{6)}$ & Hara da ${ }^{7)}$ \\
\hline 2030 (World) & $1,606-1,934$ & 1,316 & $\overline{1,977}$ & $2,000-3,000 *$ & $1,700^{*, * *}$ & $1,600^{*, * * * *}$ \\
\hline \multicolumn{7}{|c|}{ Modelling approaches IU (intensity of use) hypothesis: coupling the steel demand to income } \\
\hline \multicolumn{7}{|c|}{$\begin{array}{l}\text { * The figures in Vuuren model, Kosugi model, Harada model are read by us from the graphs of models' output. } \\
\text { ** The figures in the Kousugi model are given as finished steel consumption. We converted to apparent crude steel } \\
\text { consumption using a multiplication factor of } 2000 \text { experience (Finished steel: 761, Crude steel: 848). } \\
\text { *** The figures in the Harada model are not the World total but "Brics + G6" (USA, UK, Japan, Italy, Germany, } \\
\text { France. Russia. India. China. Brazil). }\end{array}$} \\
\hline
\end{tabular}

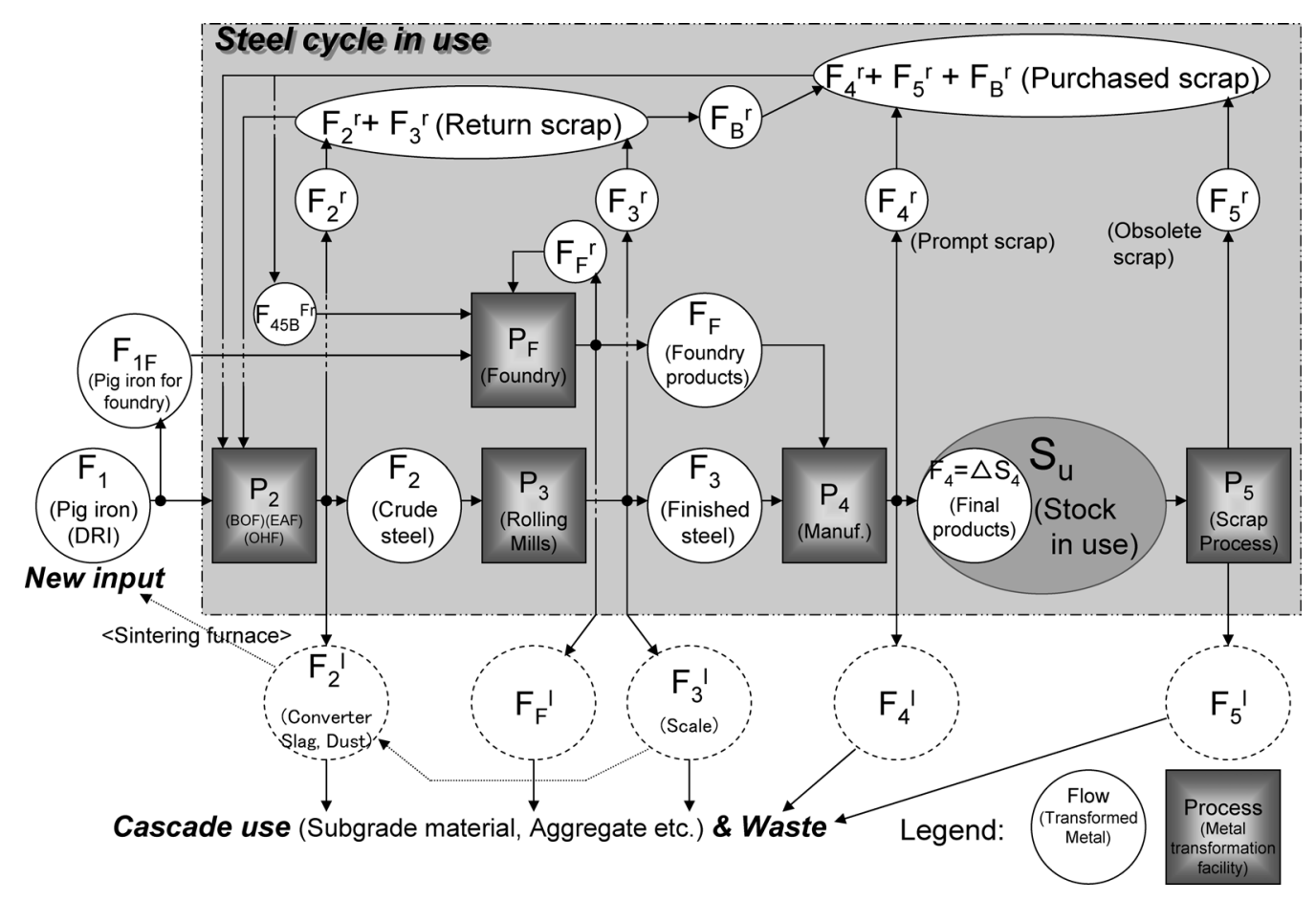

Fig. 5. Overview of the material flow analysis - World steel cycle in use.

\section{Modeling Approaches}

\subsection{Concept of Model-Utility of Stock Hypothesis-}

As noted above, it is not effective to apply the Intensity of Use hypothesis to the total world figures of iron source. When this hypothesis is applied to the country-by-country demand of iron source, it can be explained that the resumption of worldwide crude steel production since 2000 as shown in Fig. 2 is due to the demand expansion of iron source in initial economic growth stage of developing countries such as China. In this study, however, we formulated a new rational hypothesis, because there are countries where the Intensity of Use hypothesis is not applied well, function shapes of the hypothesis vary from country to country, ${ }^{1)}$ and a one-region world model of energy or paper can explain the relationship between the demand and the economic growth according to other studies. ${ }^{8,9)}$

In order to formulate a rational hypothesis, we supposed that economic growth is a driver to increase utility, which means that utility is a function of GDP. Furthermore, we focused our attention on the fact that the utility of steel, which is one of bulk materials and constructional materials, sustains for years after its purchase, although the utility of energy or paper is exhausted shortly after its purchase. Quantity possessed by users rather than purchase quantity should be regarded as utility as far as steel is concerned, while purchase quantity can be regarded as utility of energy or paper. Therefore, we formulated a hypothesis which assumes that stock of constructional materials in use is a function of GDP and called the Utility of Stock hypothesis. In this study, we computed the world steel stock and analyzed the relationship between the steel stock and the GDP in order to test the Utility of Stock hypothesis.

\subsection{Material Flow to Compute Steel Stock}

Figure 5 shows the material flow to compute the world steel stock. In this figure, $\mathrm{P}_{n}$ represents a process to transform iron or steel such as steelmaking process, rolling process. The steel cycle in use covers the processes from steelmaking $\left(\mathrm{P}_{2}\right)$ and foundry $\left(\mathrm{P}_{\mathrm{F}}\right)$ to obsolete scrap handling $\left(\mathrm{P}_{5}\right)$.

$F_{n}$ represents a material flow, whose unit is Fe equivalent ton. We suppose that stocks in processes of manufacturing and distribution are negligible, or consumption is approximated by production. ${ }^{10)}$ Therefore, the following equation is assumed. $* 4$

$$
F_{n}=F_{n+1}+F_{n+1}^{\mathrm{r}}+F_{n+1}^{1} \quad(n=2,3) .
$$

$F_{n}^{\mathrm{r}}$ is a flow which is recycled within the steel cycle in

${ }^{*} 4$ When $n=1, F_{1}-F_{1}^{\mathrm{F}}+F^{\mathrm{r}}-F_{45 \mathrm{~B}}^{\mathrm{Fr}}=F_{2}+F_{2}^{\mathrm{r}}+F_{2}^{1}$. 
Table 2. Overview of existing studies for steel stock.

\begin{tabular}{|c|c|c|c|c|c|}
\hline Researcher & $\begin{array}{l}\text { Science and Technology } \\
\text { Agency } \\
\text { (Government of Japan) }{ }^{11)}\end{array}$ & $\begin{array}{l}\text { Japan Ferrous Raw } \\
\text { Materials Association }{ }^{12)}\end{array}$ & Shimomura ${ }^{13), \text { Note } 1}$ & Muller ${ }^{14), ~ N o t e ~} 2$ & Neelis ${ }^{2)}$ \\
\hline $\begin{array}{l}\text { Calculated } \\
\text { value }\end{array}$ & $\begin{array}{l}\text { Steel stock in use } \\
\text { ( } 4 \text { major sectors: } \\
\text { construction, automobile, } \\
\text { ship, machinery) }\end{array}$ & $\begin{array}{l}\text { All steel stock (including non- } \\
\text { recycled obsolete products) }\end{array}$ & $\begin{array}{l}\text { All steel stock (including non- } \\
\text { recycled obsolete products) }\end{array}$ & Steel stock in use & Steel stock in use \\
\hline Nation covered & Japan & Japan & World & U.S.A. & World \\
\hline Year covered & 1983 & $1870-2005$ & $1865-2003$ & $1900-2004$ & $1900-2003$ \\
\hline Approach & Bottom-up approach & \multicolumn{4}{|c|}{ Top-down approach } \\
\hline $\begin{array}{l}\text { Formula of } \\
\text { computation }\end{array}$ & $\begin{array}{c}\mathrm{S}_{4}(" \text { Steel stock") }= \\
\sum(\text { "inventory of sectors" * } \\
\text { "steel concentration") }\end{array}$ & $\begin{array}{l}\mathrm{F}_{3}+\mathrm{F}_{\mathrm{F}}-\left(\mathrm{F}_{4}{ }^{r}+\mathrm{F}_{5}{ }^{r}\right)+\text { "Net indirect } \\
\text { import of steel in products" } \\
\text { "Finished steel" - } \\
\text { "Purchased scrap" + "Net } \\
\text { indirect import") }\end{array}$ & $\begin{array}{l}\Delta \mathrm{S}_{4} \text { ("Annual increm } \\
\mathrm{F}_{1}+\text { "Iron ore used in open- } \\
\text { hearth furnace" }\end{array}$ & $\begin{array}{l}\text { ent of steel stock" })= \\
\left(\mathrm{F}_{3}+\mathrm{F}_{\mathrm{F}}\right)-\mathrm{F}_{4}{ }^{\mathrm{r}}-\left(\mathrm{F}_{5}{ }^{\mathrm{r}}+\mathrm{F}_{5}{ }^{\prime}\right) \\
(" \mathrm{Finished} \text { steel and Foundry } \\
\text { products" - "Prompt scrap" } \\
- \text { "Obsolete products") }\end{array}$ & $\begin{array}{l}\left(\mathrm{F}_{2}+\mathrm{F}_{\mathrm{F}}\right)-\left(\mathrm{F}_{3}{ }^{r}+\mathrm{F}_{4}{ }^{r}\right)-\left(\mathrm{F}_{5}{ }^{r}+\mathrm{F}_{5}{ }^{\prime}\right) \\
\text { ("Crude steel and Foundry } \\
\text { products" - "Return scrap } \\
\text { and Prompt scrap" - } \\
\text { "Obsolete products") }\end{array}$ \\
\hline Data sources & $\begin{array}{l}\text { "inventory of sectors": } \\
\text { accumulated raw data } \\
\text { "steel concentration": } \\
\text { raw data as of } 1983\end{array}$ & $\begin{array}{l}F_{3}: \text { raw data } \\
\left(F_{4}{ }^{r}+F_{5}{ }^{r}\right): \text { raw data } \\
\text { "Net indirect import": values } \\
\text { derived by multiplication of } \\
\text { net imports of products (raw } \\
\text { data) and their steel } \\
\text { concentration (raw data at a } \\
\text { point) }\end{array}$ & $\begin{array}{l}F_{1}: \text { raw data } \\
\text { "Iron ore used in open-hearth } \\
\text { furnace": estimation by the } \\
\text { author }\end{array}$ & $\begin{array}{l}\mathrm{F}_{3}: \text { raw data } \\
\mathrm{F}_{\mathrm{F}}: \text { raw data } \\
\mathrm{F}_{4}{ }_{4}^{\mathrm{r}} \text { : values derived by } \\
\text { multiplication of industry yield } \\
\text { factors } \\
\mathrm{F}_{5}{ }^{\mathrm{r}}+\mathrm{F}_{5}^{\prime}: \text { model of product } \\
\text { lifetime }\end{array}$ & $\begin{array}{l}\mathrm{F}_{2}: \text { raw data } \\
\mathrm{F}_{\mathrm{F}} \text { : values derived by } \\
\text { multiplication of foundry ratio } \\
\mathrm{F}_{3}{ }^{r} \text { : values derived by } \\
\text { multiplication of return scrap } \\
\text { ratio } \\
\mathrm{F}_{4}{ }^{r} \text { : values derived by } \\
\text { multiplication of prompt scrap } \\
\text { ratio } \\
\mathrm{F}_{5}{ }^{r}+\mathrm{F}_{5}^{\prime} \text { : model of product } \\
\text { lifetime (based on Muller) }\end{array}$ \\
\hline
\end{tabular}

Note 1: The total stock in use in the U.S. is estimated in a similar way to track cumulative production of primary iron by Sullivan. ${ }^{15)}$

Note 2: The total stock in use in Japan is estimated in a similar model of different economic lifetimes by Daigo et al. ${ }^{10)}$

use. $F_{n}^{1}$ is a flow which goes out from the steel cycle in use. $F^{\mathrm{r}}$ and $F^{1}$ are defined as follows.

$$
\begin{gathered}
F^{\mathrm{r}}=F_{2}^{\mathrm{r}}+F_{3}^{\mathrm{r}}+F_{4}^{\mathrm{r}}+F_{5}^{\mathrm{r}} \cdots \\
F^{1}=F_{2}^{1}+F_{3}^{1}+F_{4}^{1}+F_{5}^{1}+F_{\mathrm{F}}^{1}
\end{gathered}
$$

$F_{5}$ represents obsolete products which come from ironcontaining products such as automobiles and buildings after their lifetime: those include products produced before the reference year. The following equation is assumed.

$$
F_{5}=F_{5}^{\mathrm{r}}+F_{5}^{1}
$$

Some of obsolete products are stocks of obsolete products ${ }^{5}$ which have not yet been decided to belong to $F_{5}^{\mathrm{r}}$ or $F_{5}^{1}$ for over a year (the observation period). For the purpose of obtaining the in-use steel stock, it does not make any difference that parts of stocks of obsolete products which will go out from the steel cycle in use over time are counted among $F_{5}^{1}$ in advance. The other parts, which will be recycled within the steel cycle in use as scrap over time, can not be obtained from the available data, and we suppose these parts can be negligible.

$F_{\mathrm{F}}^{\mathrm{r}}$, which is scrap for recycling generated from foundry process $\left(\mathrm{P}_{\mathrm{F}}\right)$, is supposed to be recycled only within foundry process. Therefore, the following equation is obtained.

$$
F_{1}^{\mathrm{F}}+F_{45 \mathrm{~B}}^{\mathrm{Fr}}=F_{\mathrm{F}}+F_{\mathrm{F}}^{1}
$$

Consequently, the steel stock is composed of $F_{4}$, which is iron content of end products such as automobiles and build- ings, and $F^{1}$, which is iron content spilled out from the steel cycle in use. The steel stock in year $t$ is defined as $S(t)$, and the in-use steel stock in year $t$ is defined as $S_{\mathrm{u}}(t)$. Due to the availability of data, stocks were computed as the time-series cumulative amount since 1870 as follows.

$$
\begin{aligned}
S_{\mathrm{u}}(t) & =\sum_{\tau=1870}^{t}\left(F_{4}(\tau)-F_{5}(\tau)\right) \\
S(t) & =S_{\mathrm{u}}(t)+\sum_{\tau=1870}^{t} F^{1}(\tau)
\end{aligned}
$$

Concerning $F_{n}^{1}$, for example, $F_{2}^{1}$ is iron content of slag, dust and scale, which is not recycled within the steelmaking plant. Some $F_{2}^{1}$ are recycled as pig iron in a sintering process, and some are in cascade use such as subgrade material, and others are landfilled as solid waste. Pig iron from $F_{2}^{1}$ should not be included in $S(t)$, but we suppose that this amount can be negligible.

As mentioned in Sec. 3.5, the data used in this study were obtained from statistics published in annual reports, and therefore the observation period is one year.

\subsection{Existing Studies on Steel Stocks}

Table 2 typified existing studies on steel stocks by employing the material flow shown in Fig. ${ }^{2,10-15)}$ Steel stocks are in many cases estimated for a country, supposably due to constraints of data availability. According to our literature search, only two articles by Y. Shimomura et al., ${ }^{13)}$ and M. Neelis et $a l^{2}{ }^{2} * 6$ compute world steel stocks.

Methods to estimate steel stock are divided into two large groups: the bottom-up approach and the top-down ap-

\footnotetext{
${ }^{*}$ Stocks of obsolete products are accumulations of obsolete products that have exited Use but that have not entered Scrap Processing and Waste Management, such as end-of-life vehicles, illegal dumps, or temporary storage sites. ${ }^{14)}$

${ }^{* 6}$ The article of M. Neelis et al. shows the amount of steel stock for the USA but not for the world total, although it gives a detailed description about a method to estimate the world steel stock.
} 
proach. The bottom-up approach is to quantify inventories of iron-containing products in use such as automobiles and buildings and their iron concentrations to calculate steel stocks. This approach has advantage to compute precise steel stocks, but disadvantage to require significant cost and work. In Japan, for example, this approach has been taken only once in 1985 by the Science and Technology Agency to compute the Japanese steel stock in March 1983.

The top-down approach is based on the data of iron and steel production. This approach has advantage to fit analysis of time-series. Disadvantages are lack of scrap data, which are needed to estimate for developing countries and past years of developed countries, and issue of indirect export and import of iron-containing products when steel stocks of a country are estimated. In order to estimate "inuse" steel stocks, in addition, it is necessary to presuppose the usage period (lifetime) of end products containing iron and estimate the amount of obsolete products $\left(F_{5}\right)$, which includes products produced before the reference year.

\subsection{Method to Compute Steel Stock}

With reference to the existing studies mentioned above, the steel stock $S(t)$ was calculated in the simplest method for estimation in this study. The top-down approach was taken to analyze time-series. As the world total was computed, it was not necessary to take into account the export and import of steel products, those of iron-containing products (indirect trade) and of scrap.

In this study, the steel stock $S(t)$ was obtained by time-series cumulative accounting of the iron input into the steel cycle in use, in other words, the iron content of iron ore consumed, from 1870 till year $t$. The equation is as follows.

$$
S(t)=\sum_{\tau=1870}^{t} F_{1}(\tau)
$$

While the iron content of iron ore input directly into steel converter (basic oxygen furnace) or open-hearth furnace is not included, the iron content of converter slag that is recycled as pig iron in a sintering process is doubly counted in
$S(t)$. We suppose that these amounts are negligible small.

The steel stock $S(t)$ can be an approximate quantity of inuse steel stock $S_{\mathrm{u}}(t)$, provided that $F_{n}^{1}$, which is a flow going out from the steel cycle in use, is negligible small. Steel is easily recycled because it is readily distinguishable on the basis of magnetic property. Concerning Japan, for example, there is a proposition that virtually no solid waste from steel cycle in use is observed and the recycling rate of steel is more than $97 \%{ }^{16)}$ Therefore, we think that the presumption of negligible $F_{n}^{1}$ is worth considering. ${ }^{7}$

\subsection{Data to Compute Steel Stock and Test the Utility of Stock Hypothesis}

The iron input into the steel cycle in use to compute the steel stock was obtained as sum of iron content of pig iron production and DRI (direct-reduced iron) production. The data sources of the world's pig iron production are the Statistishes Bundesamt Deutschland over the period 1870-1966 and the IISI (International Iron and Steel Institute) over the period 1967-2005. Concerning the data of Statistishes Bundesamt Deutschland, the available data in the period of 1870-1910 are at intervals of 5 years, and the data from 1914 to 1919 are missing. The missing data were made up for by linear interpolation between the contiguous available data. The data source of the world's DRI production is the IISI over the period of 1976-2005. We assume that pig iron contains $96 \%$ iron and that DRI contains $91 \%$ iron.

GDP to test the Utility of Stock hypothesis was used on the ppp (purchasing power parity) scale. The data sources of the world's GDP ppp are Maddison ${ }^{17)}$ over the period 1870-1974 and the World Bank $^{18)}$ over the period 1975-2005. Concerning the data of Maddison, the total world data in the period of 1871-1889, 1901-1912 and 1914-1949 are missing. The missing data were made up for by counting up the data of 16 major countries and interpolating linearly "the total of 16 major countries' data/the total world data" between the contiguous available data. As the unit of Maddison is 1990 international \$, the data of Maddison were converted to 2000 international \$ with multiplying by "the data of World Bank (2000 international

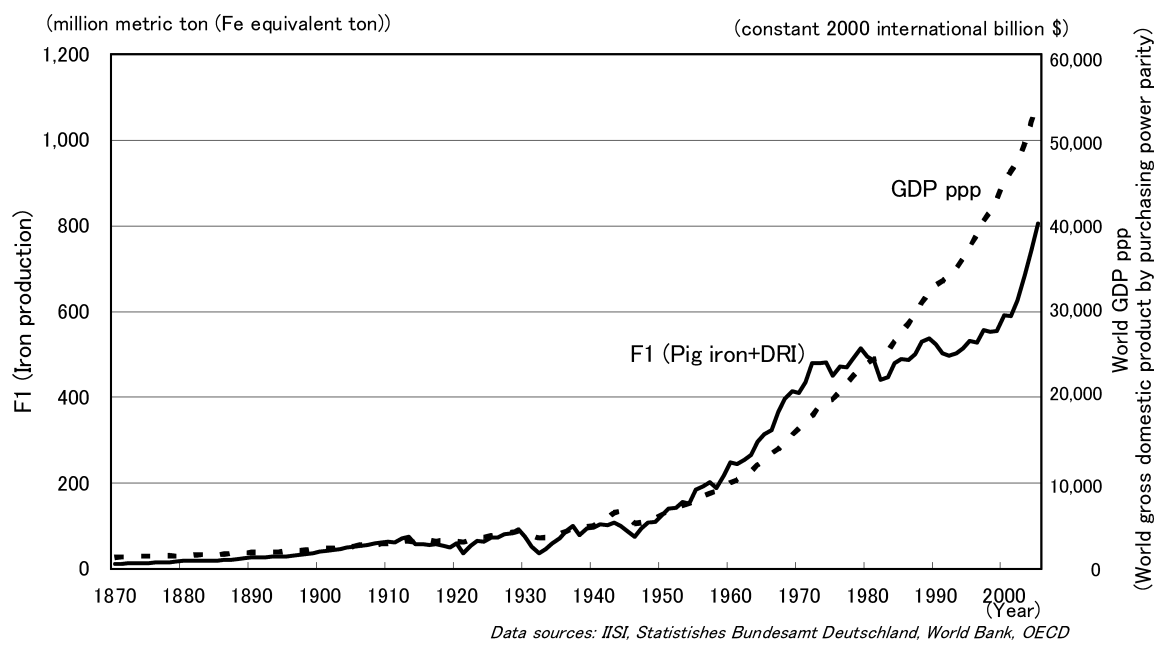

Fig. 6. Iron input into world steel cycle in use, GDP ppp (gross domestic product by purchasing power parity), $1870-2005$.

\footnotetext{
${ }^{* 7}$ There is another estimation that some 0.9 billion tons are in-use stocks of the total of 1.2 billion tons of overall Japanese stocks (steel stocks) in $2000 .{ }^{10)}$
} 
\$)/the data of Maddison (1990 international \$)" in 1975. Figure 6 shows the data of the iron input into the world steel cycle in use and GDP ppp, which were obtained by the above-mentioned method.

\section{Results of Computation and Discussion}

\subsection{Results of Computation}

Figure 7 shows the result to compute the steel stock by Eq. (8). Figure 8 shows the relationship and the result of regression analysis, when the steel stock is a function of the GDP. There is a clear correlation: the correlation coefficient $R=0.966$. When " $X(t)$ " (constant billion $\$$ ) symbolizes the GDP in year $t$, Eq. (9) is obtained for the steel stock " $S(t)$ " (million metric tons).

$$
S(t)=0.564 \times X(t)-87.0
$$

\subsection{Discussion}

\subsubsection{Confirmation of Correlation}

With reference to the correlation between the steel stock and the GDP, statistical significance is demonstrated by Ftest, t-test and p-value of GDP. ${ }^{19)}$ However, serial correlation can be judged, as the Durbin-Watson statistic is nearly 0 . This indicates a lack of explaining variable or possibilities that erroneous values of standard error or t-test can be obtained. In addition, we consider the possibility that the sensitivity of analysis may become low as the explained variable is cumulative amount. $* 8$

Therefore, we examined the residual information in regard to serial correlation. Figure 9 shows the residual plots - it has $X(t)$ (World GDP ppp) on the $x$-axis and the residuals $(S(t)-(0.564 X(t)-87.0))$ on the $y$-axis. The residuals are positive when $X(t)$ are relatively small, and the residuals are negative when $X(t)$ are relatively big. The reason that the Durbin-Watson statistic is nearly 0 is due to the

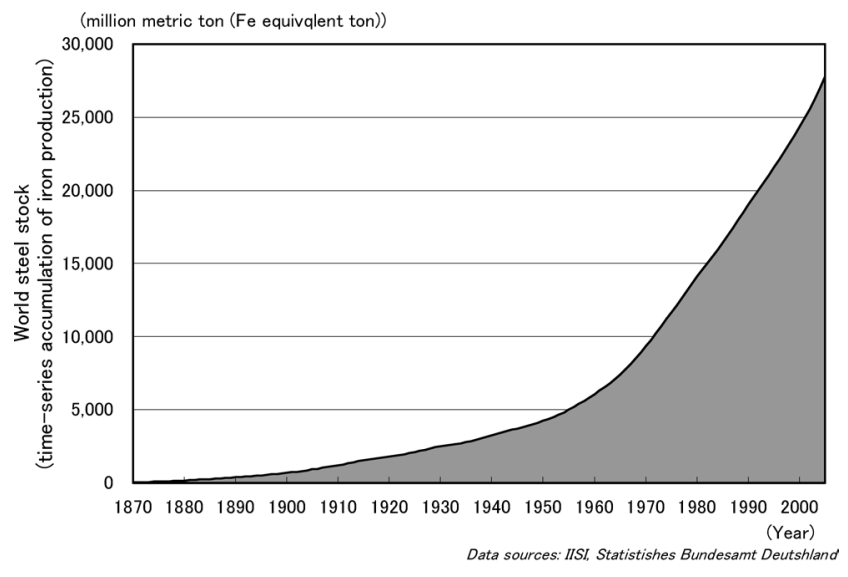

Fig. 7. World steel stock, 1870-2005.

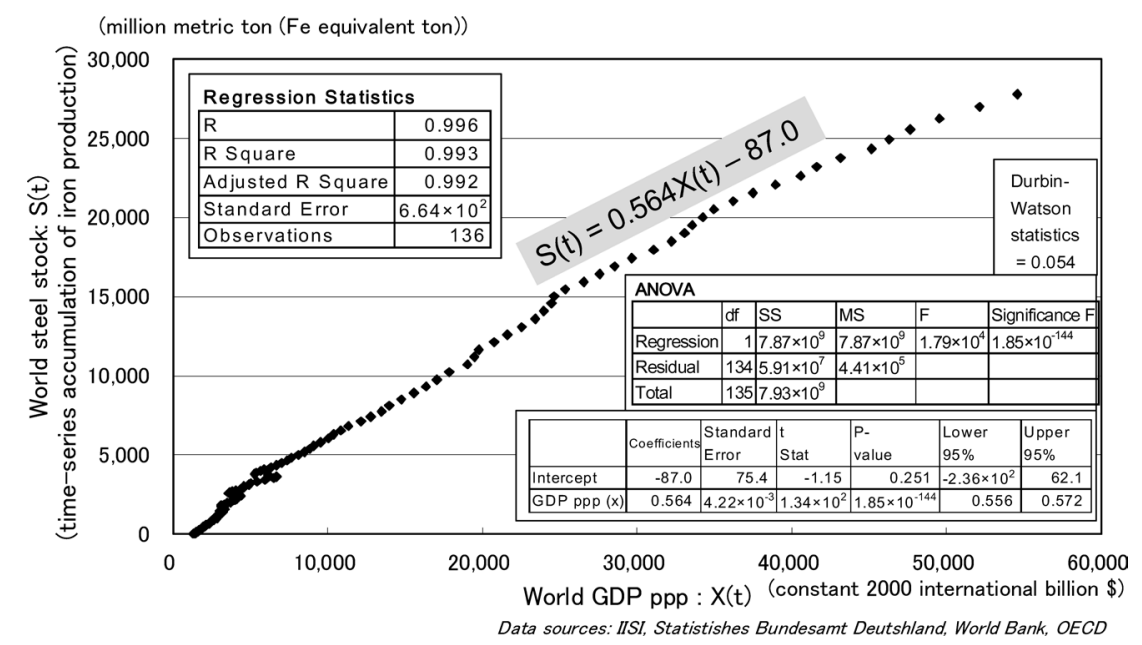

Fig. 8. Relationship between World GDP ppp (gross domestic product by purchasing power parity) and Steel stock, 1870-2005.

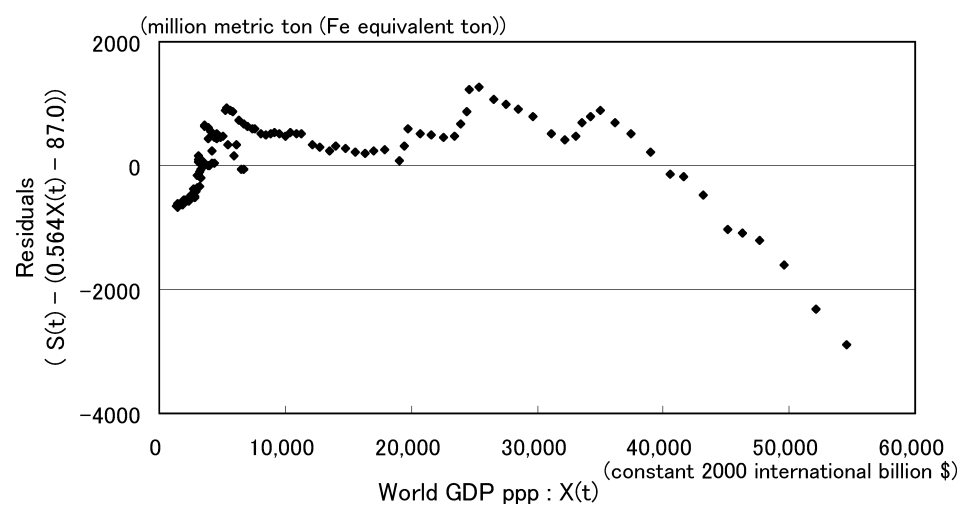

Fig. 9. World GDP ppp (gross domestic product by purchasing power parity) Residual Plot (Relationship between World GDP ppp and Steel stock).

\footnotetext{
${ }^{*}$ Coefficient of correlation is, however, not always improved when the explaining variable becomes cumulative or integration value.
} 


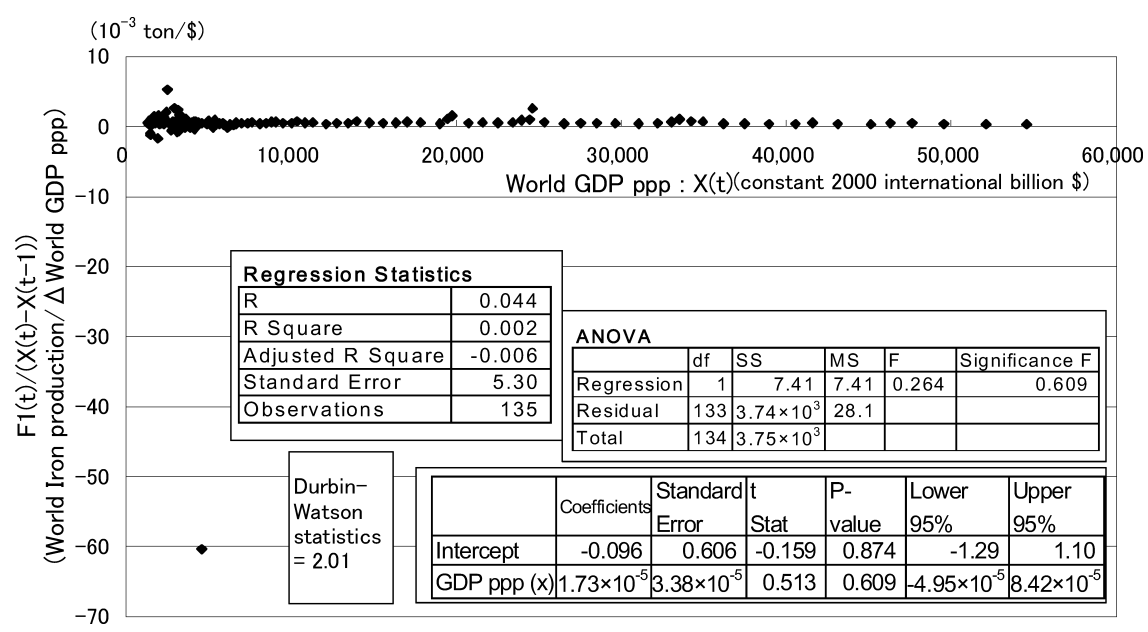

Fig. 10. Relationship between World GDP ppp (gross domestic product by purchasing power parity) and Iron production/ $\triangle$ GDP ppp, 1870-2005.

fact that the relationship between World GDP ppp and Steel stock is not a straight line to be exact but a curve of gradual arc.

Next, we examined the sensitivity of analysis by using the following equations: after approximating the integration value by the cumulative value, the difference value was obtained as the approximation value of derivative value.

$$
\begin{aligned}
S(t) & =\sum_{\tau=1870}^{t} F_{1}(\tau) \approx \int F_{1} d X \ldots . \\
\frac{d S(t)}{d X(t)} & \approx \frac{S(t)-S(t-1)}{X(t)-X(t-1)} \\
& =\frac{F_{1}(t)}{X(t)-X(t-1)}=0.564
\end{aligned}
$$

Figure 10 shows the relationship and the result of regression analysis, when the explained variable is the " $F_{1}(t) /(X(t)-X(t-1))$ " and the explaining variable is the GDP. The Durbin-Watson statistic is nearly 2 and it indicates no serial correlation. Furthermore, there is virtually no correlation: the correlation coefficient $\mathrm{R}=0.044$. That means that there is little or no correlation between $F_{1}$ and GDP. The scatter plot of Fig. 10 demonstrates that " $F_{1}(t) /(X(t)-X(t-1))$ " is maintained virtually constant and Eq. (11) is confirmed. Therefore it is statistically siginificant to suppose that the relationship between world GDP ppp and steel stock can be approximated as linear by Eq. (9).

\subsubsection{Verification of the Stock of Utility Hypothesis and Recycling Efficiency of Steel}

As identified above, the Stock of Utility hypothesis is statistically-significant. Although significant correlation is not sufficient condition but only necessary condition to establish a causal relationship, the Stock of Utility hypothesis has some credible rational as mentioned in Sec. 3.1. Therefore, "in-use steel stock" can be represented as a function of "GDP."
Equation (12) is obtained from Eq. (11).

$$
F_{1}(t)=0.564 \times(X(t)-X(t-1))
$$

$F_{1}(t)$ depends not on the absolute GDP but on the variation of GDP. Therefore, in the case of zero growth of world economy, in other words, when $X(t)-X(t-1)=0$, then $F_{1}(t)=0$. That means pig iron production from blast furnace will be zero and crude steel will be produced only from scrap if the world GDP remains at the same level. In addition, the presumption of negligible $F_{n}^{1}$, which is a flow that goes out from the steel cycle in use, is estimated to be meaningful: the recycling rate of steel is estimated to be high. ${ }^{9}$

Table 3 shows the relationship between energy, paper, iron source and GDP.

\subsection{Future Issues to Be Studied-Toward Outlook for Iron Source Demand-}

The decoupling between the iron and steel demand and the economic growth has been observed, in other words, the world production of pig iron or crude steel had expanded until 1973, then crawled during almost 30 years, and has recently increased again, while the world GDP has increased continuously. With reference to this observation, there has been no explanation from macro dynamics or with total world figures, although there have been micro explanations about individual situations in China etc. For the first time with total world figures, the Utility of Stock hypothesis enables us to rationalize the recent decoupling between the iron ore demand and the economic growth.

Equation (12) will enable a forecast of iron ore demand, having an existing prospect of GDP (for example by IPCC) provided as an exogenous variable. As mentioned in Sec. 4.2.2, however, the Utility of Stock hypothesis leads to the conclusion that the world production of pig iron from blast furnace will be zero if the world economy attains zero growth. Although it is unrealistic to forecast zero growth of the world economy, it is more unrealistic to forecast that the world production of pig iron from blast furnace will be zero

${ }^{* 9}$ There is another possibility that the recycling rate of steel is not high but has improved or technical innovations such as introducing high-strength steel have progressed. Alternatively, it may be due to the effect that $F_{1}(t)$ has become relatively-large during the usage period (lifetime) of iron-containing end products. 
Table 3. Relationship between GDP and energy \& materials.

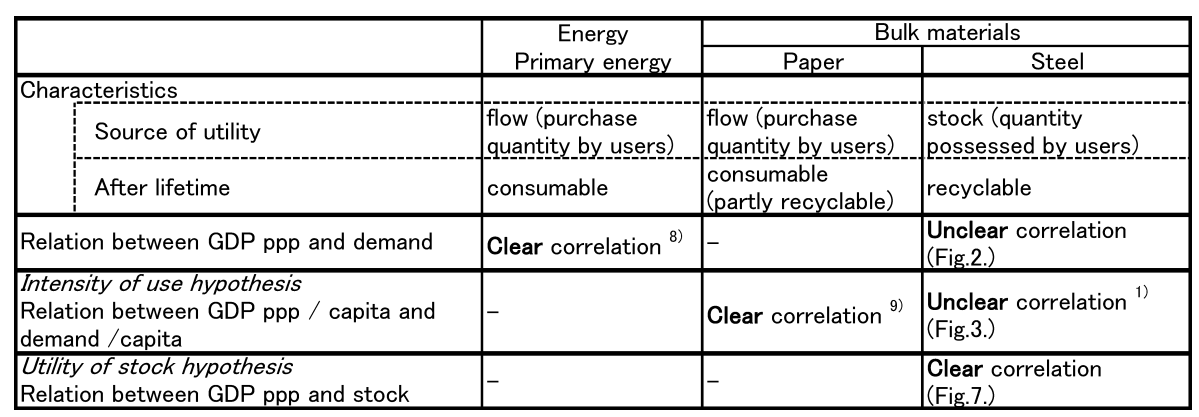

in that case, because recycling rate of steel is not $100 \%$. On the one hand, therefore, care should be taken when the Utility of Stock hypothesis will be applied to a case of low economic growth. On the other hand, as shown in Figs. 8 and 9, the income elasticity of steel stock, which is calculated as the ratio of the percent change in quantity of steel stock to the percent change in GDP, has recently declined slightly. In cases where the world economic growth will continue as ever or expand, the possibilities should be taken into account that the income elasticity will decline as ever or more drastically. $* 10$

Furthermore, future study should consider more precise calculations of in-use steel stock, although available statistics and data concerning flows of iron-containing goods such as scrap are incomplete and have variable uncertainties.

In the near future, we would like to study an analysis of scrap demand and in-use steel stock with total world figures, because steel is produced either primary iron (made from iron ore) or secondary iron (scrap). After that study, we would like to test the validity by comparing the assumed values based on these analysis to the actual values.

\section{Conclusion}

In this study, we focused on the utility, which is a measure of the user's relative satisfaction from possessing goods, and supposed that the economic growth is a driver to increase the utility. The Utility of Stock hypothesis, which assumes that the in-use stock is a function of GDP, was studied.

The Utility of Stock hypothesis achieved specifying the economic growth as a possible factor that affects the amount of steel stock. For the first time with total world figures, the result enables us to rationalize the recent decoupling between the world growth of iron source demand and the economic growth.

\section{Acknowledgements}

In the course of this research, we received valuable advice and information from Dr. Kimitoshi Yonezawa of the Nippon Steel Corp., Professor Yoshihiro Adachi, Professor Yasunari Matsuno and Professor Tsuyoshi Adachi of the University of Tokyo. We are very grateful for their contributions.

\section{REFERENCES}

1) S. Kozawa, K. Kimitoshi and F. Tsukihashi: Tetsu-to-Hagané, 93 (2007), 715.

2) M. Neelis and M. Patel: Long-term Production, Energy Consumption and $\mathrm{CO}_{2}$ Emission Scenarios for the Worldwide Iron and Steel Industry, Report prepared by the Department of Science, Technology and Society/Copernicus Institute at Utrecht University, Utrecht, (2006).

3) I. Hidalgo, L. Szabo, J. C. Ciscar and A. Soria: Energy, 30 (2005), 583.

4) Vleem 2, Final Report, EC/DG Research Contract ENG1-CT 200200645, http://www.vleem.org/, (accessed 2008-2-11).

5) D. P. van Vuuren, B. J. Strengers and H. J. M. De Vries: Resour. Policy, 25 (1999), 241.

6) T. Kosugi: Seisakukagaku, 13 (2006), No. 2, 2.

7) National Institute for Materials Science: Press release on 15 Feb. 2007 (in Japanese) -2050nen madeni sekaitekina sigenseiyaku no kabe (A wall of global resource constraint by 2050), Tsukuba, (2007), http:/www.nims.go.jp/jpn/news/press/press178.html (accessed 2007-5-2).

8) Organisation for Economic Co-operation and Development, International Energy Agency: World Energy Outlook 2004, Paris, (2005), Fig. 1.1.

9) Vleem 2, Final Report, Figure 45, EC/DG Research Contract ENG1CT 2002-00645, http://www.vleem.org/, (accessed 2008-2-11).

10) I. Daigo, Y. Igarashi, Y. Matsuno and Y. Adachi: ISIJ Int., 47 (2007), 1065.

11) Science and Technology Agency: Wagakuni ni okeru Tekkoutikusekiryou ni kannsuru Tyousa (Study for Steel Stock in Japan), Tokyo, (1985).

12) Japan Ferrous Raw Material Association: Quarterly Tetsugen, Vol. 1, Tokyo, (1999).

13) Y. Shimomura and S. Hayashi: Bull. Iron Steel Inst. Jpn., 10 (2005), 479.

14) D. B. Muller, T. Wang, B. Duval and T. Graedel: Exploring the Engine of Anthropogenic Iron Cycles, PNAS Early Edition, New Haven, (2006), http: /www.pnas.org/cgi/doi/10.1073/pnas. 0603375103 (accessed 2006-10-23).

15) D. E. Sullivan: Metal Stocks in Use in the United States, U.S. Geological Survey, Denver, (2005), http://pubs.usgs.gov/fs/2005/3090/ 2005-3090.pdf (accessed 2008-3-9).

16) Japan Technical Information Service Corporation: Private communication, (15, March, 2007).

17) A. Maddison: The World Economy, Development Center of the Organization for Economic Co-operation and Development, Paris, (2006).

18) World Bank: World Development Indicators on CD-ROM, Washington, D.C., (2007).

19) T. Kariya (editorial supervisor), Bank of Japan (ed.): Keiryoukeizaibunnseki no Kiso to Ouyou (Base and Application of Economic Analysis), Toyo Keizai Inc., Tokyo, (1985), 87.

\footnotetext{
${ }^{* 10}$ In addition, possibilities can not be ignored that consumption in the future will be determined by supply constraints, which are short-term constraints such as underdeveloped mining and local scarce capacity of iron and steel production, or long-term constraints such as natural resource degradation and global warming.
} 